\title{
Construction and Immunogenicity of a Recombinant Pseudorabies Virus Variant With $\mathrm{TK} / \mathrm{gl} / \mathrm{gE} / 11 \mathrm{k} / 28 \mathrm{k}$ Deletion
}

\author{
Shijun Yan ${ }^{\dagger}$, Baicheng Huang ${ }^{\dagger}$, Xiaofei Bai, Ying Zhou, Linghua Guo, Tongyan Wang, \\ Yihong Shan, Yuzhou Wang, Feifei Tan* and Kegong Tian*
}

National Research Center for Veterinary Medicine, Luoyang, China

OPEN ACCESS

Edited by: Zhenhai Chen,

Yangzhou University, China

Reviewed by:

Wang Yongqiang,

China Agricultural University, China

Lok Raj Joshi,

Cornell University, United States Mayara Fernanda Maggioli, Oklahoma State University, United States

*Correspondence:

Feifei Tan

tf0801@126.com

Kegong Tian

vetvac@126.com

tThese authors have contributed equally to this work

Specialty section: This article was submitted to Veterinary Infectious Diseases, a section of the journal Frontiers in Veterinary Science

Received: 19 October 2021 Accepted: 13 December 2021

Published: 25 January 2022

Citation:

Yan S, Huang B, Bai X, Zhou Y, Guo L, Wang T, Shan Y, Wang Y, Tan F and

Tian K (2022) Construction and Immunogenicity of a Recombinant Pseudorabies Virus Variant With

TK/gl/gE/11 K/28k Deletion.

Front. Vet. Sci. 8:797611.

doi: 10.3389/fvets.2021.797611
In China, the re-emerging pseudorabies virus (PRV) variant has caused large-scale outbreaks of pseudorabies in swine herds with classical PRV vaccine immunization since late 2011. Here, a recombinant PRV with $\mathrm{TK} / \mathrm{gl} / \mathrm{gE} / 11 \mathrm{k} / 28 \mathrm{~K}$ deletion was constructed based on variant HN1201 strain isolated in 2012, by the bacterial artificial chromosome infectious clones. Compared with the parental virus, the

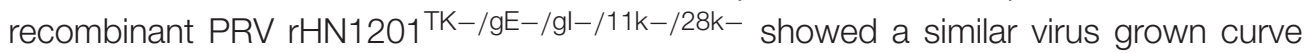
and exhibited smaller plaques. The vaccination of $\mathrm{rHN1201}{ }^{\mathrm{TK}-/ \mathrm{gE}-/ \mathrm{gl}-/ 11 \mathrm{~K}-/ 28 \mathrm{~K}-}$ could elicit an earlier and higher level of gB antibody, and the neutralizing antibodies elicited by $\mathrm{rHN}_{12} 201^{\mathrm{TK}}-/ \mathrm{gE}-/ \mathrm{gl}-/ 11 \mathrm{k}-/ 28 \mathrm{k}$ - were effective against both PRV classical and variant strains. Clinically, the body temperature of the pigs immunized with

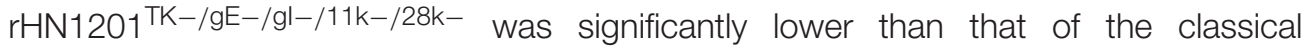
PRV vaccine immunized pigs, and the recombinant PRV could provide effective protection against the challenge with the PRV variant. These results imply that

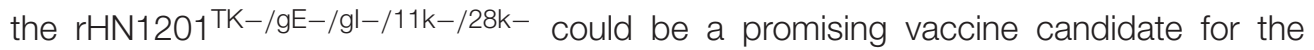
prevention of the current epidemic of pseudorabies in China.

Keywords: pseudorabies virus (PRV), gene deletion, bacterial artificial chromosome, vaccine, immune protection

\section{INTRODUCTION}

Pseudorabies (PR), also called Aujeszky's disease, is caused by the infection of an alpha-herpesvirus Pseudorabies virus (PRV) (1). The double-stranded DNA genomic sequence of PRV is $\sim 145 \mathrm{~kb}$ in size, containing almost 70 open reading frames (ORFs) that encode 70-100 viral proteins (2).

The herpesvirus PRV has a broad host range, which is known to cause acute fatal disease in a variety of mammals (3-5). The PRV infection may lead to acute symptoms and even death in piglets, and the clinical signs of coughing, sneezing, lethargy, nervousness, uncoordinated movements, and abortion in sows (1), resulting in heavy economic losses in the pig industry. Like other alpha-herpesviruses, PRV is characterized by a lifelong latent infection in the host peripheral nervous system. Stress-induced reactivation of latent PRV is a difficulty for PR prevention (6).

Highly efficacious gene-deleted modified-live vaccines, such as the strain PRV Bartha-K61 that attenuated from wild-type strain Bartha via multiple passages on pig kidney cells and chicken embryos, and their companion differential serological tests have been widely used to control PR during the past several decades $(7,8)$. Compared with the wild-type strain, the attenuated Bartha 
carries a large deletion in the unique short region of the genome, including the complete genes of gE and US9 (11k), and part of the US2 (28k) and gI (9). However, the emerging virulent PRV strains have caused severe PR in the vaccinated pigs in China since late 2011 (10-13), while the widely used PRV vaccines of classical strains only provide limited protection to the new-emerging PR (12). After the new-emerging PR outbreaks, a virulent PRV variant HN1201 in China was isolated, which induced high fever, anorexia, coughing, dyspnea, and systemic neurological symptoms in the infected pigs $(12,14,15)$. Multiple studies have shown that the highly virulent PRV was the causal agent of this PR epidemic $(12,14-16)$. Therefore, it is urgent to develop more effective PRV vaccines based on the emerging PRV strains for the disease control.

Bacterial artificial chromosome (BAC) infectious clone is widely used for the studies of viral genome manipulation, and then be used for evaluating the efficacy of vaccine candidates (17-20). In herpesvirus, the BAC system was a powerful tool for generating recombinant viruses, which promotes the understanding of viral pathogenesis, vaccine development, and gene therapy (21). The gI, gE, and TK genes were critical for PRV virulence, but with no obvious effect on viral immunogenicity $(22,23)$. The gene of $11 \mathrm{k}$ is required for the efficient spread of PRV in the nervous system $(24,25)$. The deletion of $28 \mathrm{k}$ gene in the attenuated PRV vaccine strain strongly suggested an important role of $28 \mathrm{k}$ in virulence determination (26), and more recently, the $28 \mathrm{k}$ gene deletion showed an enhancement of PRV titers in vitro (27).

Here, a TK/gE/gI/11k/28k deleted PRV strain was generated based on a modified RPV, HN1201 ${ }^{\mathrm{TK}-}$ (15), using BAC infectious clone, and then the immunogenicity of the 5-gene-deleted vaccine candidate was evaluated in pigs.

\section{MATERIALS AND METHODS}

\section{Animals}

Pigs (28-day-old) used in this study were tested free of PRV, porcine reproductive and respiratory syndrome virus (PRRSV), classical swine fever virus (CSFV), and porcine circovirus 2 (PCV2). All the animal samples were collected according to the protocol approved by the Animal Care and Ethics Committee of National Research Center for Veterinary Medicine (Permit 20170625005).

\section{Virus and Cells}

The PRV variant HN1201 (GenBank accession no. KP722022.1) isolated in 2012 has been described previously (15). Pig kidney cells (PK-15 cells, ATCC ${ }^{\circledR}$ CCL-10) and African green monkey kidney (Vero) cells were grown in Dulbecco's modified Eagle medium (DMEM) (Gibco, CA, USA) supplemented with $10 \%$ fetal bovine serum (FBS) (Gibco), and then incubated in a humidified incubator with $5 \% \mathrm{CO}_{2}$, while the cell culture medium used during viral infection was the DMEM supplemented with $2 \%$ FBS.

\section{Generation of rHN1201 ${ }^{\mathrm{TK}-/ \mathrm{gE}-/ \mathrm{gl}-/ 11 \mathrm{k}-/ 28 \mathrm{k}-}$}

The Escherichia coli (E. coli) competent cells DY380 that harbor the plasmid pBAC-HN1201 ${ }^{\mathrm{TK}-}$ were obtained as described previously (15). The DY380 cells were electroporated with a PCR product, a positive selection marker of ampicillin (Amp) gene containing the short extensions (SE) that are homologous to the gI and $28 \mathrm{k}$ genes in both ends, to produce intermediate plasmid

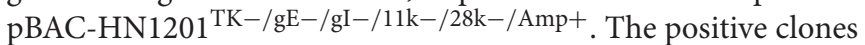
were selected on agar plates containing $100 \mu \mathrm{g} / \mathrm{ml} \mathrm{Amp} \mathrm{and}$ $30 \mu \mathrm{g} / \mathrm{ml}$ chloramphenicol, and further confirmed by digestion of BamHI. After digestion using I-SceI, the linear plasmid was transformed into DY380 cells to remove the Amp gene and get the plasmid pBAC-HN1201 $1^{\mathrm{TK}-/ \mathrm{gE}-/ \mathrm{gI}-/ 11 \mathrm{k}-/ 28 \mathrm{k}-}$.

To remove the BAC gene cassette and the Loxp residual sequence, a PCR product [a cassette of kanamycin (Kan) gene with homologous arm sequence of Cat-OriS from pBeloBAC11 plus the inverted repeat fragment of the homologous arm of PRV TK gene] was transformed into the DY380 cells containing the plasmid pBAC-HN1201 $1^{\mathrm{TK}-/ \mathrm{gE}-/ \mathrm{gI}-/ 11 \mathrm{k}-/ 28 \mathrm{k}-}$

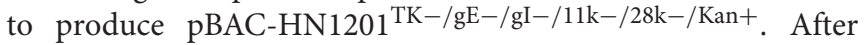
digestion using I-SceI, the linear plasmid was transformed into DY380 cells to remove the Kan gene, and finally to produce pBAC-HN1201 ${ }^{\mathrm{TK}-/ \mathrm{gE}-/ \mathrm{gI}-/ 11 \mathrm{k}-/ 28 \mathrm{k}-}$. After that, the positive clone of pBAC-HN1201 $1^{\mathrm{TK}-/ \mathrm{gE}-/ \mathrm{gI}-/ 11 \mathrm{k}-/ 28 \mathrm{k}-}$ was transfected into Vero cells to produce markerless 5-gene deleted virus rHN1201 $1^{\mathrm{TK}-/ \mathrm{gE}-/ \mathrm{gI}-/ 11 \mathrm{k}-/ 28 \mathrm{k}-}$, which was obtained after 3 rounds of purification by plaque assay.

\section{In vitro Growth Properties and Plaque Morphology}

One-step growth curve of the rescued $\mathrm{rHN} 1201^{\mathrm{TK}-/ \mathrm{gE}-/ \mathrm{gI}-/ 11 \mathrm{k}-/ 28 \mathrm{k}-}$ was assessed, and then was compared with that of the parental virus HN1201. After infection by the parental and rescued virus (MOI of 1.0), the supernatants of Vero cells were harvested at $0,4,8,12,16,20,24$, 28,32 , and $36 \mathrm{~h}$ post-infection (hpi) and stored at $-80^{\circ} \mathrm{C}$. The virus titers were determined by the $50 \%$ tissue culture infectious dose $\left(\mathrm{TCID}_{50}\right)$. Growth kinetics for each virus were tested in triplets and the resulting titers were averaged.

Plaque sizes were determined at 48 hpi in Vero cells. Briefly, in the 6-well plates with monolayer cells, the culture medium (DMEM supplied with $2 \%$ FBS) containing $1.0 \times 10^{3}$ TCID $_{50}$ of the virus was aspirated at $1 \mathrm{~h}$ after incubation, and then the cells were overlaid with $1 \%$ low-melting-point agarose in DMEM supplied with $2 \%$ FBS for plaque formation. For each virus, 100 plaques were randomly selected, and the plaque size was determined by ImageJ software (National Institutes of Health).

\section{Animal Experiment}

A total of 15 pigs (28-day-old), free of PRV, PRRSV, CSFV, and PCV2, were randomly divided into 3 groups $(n=5)$. The piglets in groups 1 and 2 were vaccinated intramuscularly with $1.0 \times 10^{5.0} \mathrm{TCID}_{50} \mathrm{rHN}_{201} \mathrm{TK}^{\mathrm{TK}-/ \mathrm{gE}-/ \mathrm{gI}-/ 11 \mathrm{k}-/ 28 \mathrm{k}-}$ and one dose of Bartha-K61, respectively. DMEM medium was used as the placebo in group 3 (unvaccinated). After vaccination, rectal temperature and clinical signs were recorded daily. The pig serum samples in days post-vaccination (dpv) of $0,8,10$, 
12,14 , and 21 were collected to monitor $\mathrm{gB}$ and neutralizing antibodies (NAbs). All pigs were challenged with HN1201 (1.0 $\times 10^{6.0}$ TCID $_{50}$ per pig) intranasally at $21 \mathrm{dpv}$. At 14 days post-challenge $(\mathrm{dpc})$, all pigs were euthanized and necropsied, and organ samples were collected for immunohistochemistry (IHC) assay.

\section{Antibody Testing}

For antibody testing, $\mathrm{gB}$ antibodies of the serum samples were evaluated by the Aujeszky gB (Pseudorabies Virus) Antibody Test Kit (BioChek, The Netherlands) according to the instructions. The PRV-specific NAbs titers were tested by serum-neutralization test (SNT). Briefly, serum samples were inactivated at $56^{\circ} \mathrm{C}$ for 30 min prior to the SNT. Two-fold serially diluted serum $(50 \mu \mathrm{l})$ was mixed with an equal volume of the HN1201 or Bartha-K61 $\left(1.0 \times 10^{2} \mathrm{TCID}_{50}\right)$ in 96 -well plates and incubated at $37^{\circ} \mathrm{C}$ for $1 \mathrm{~h}$ in an atmosphere with $5 \% \mathrm{CO}_{2}$. After incubation, $100 \mu \mathrm{l}$ of PK-15 cell suspension containing $2.0 \times 10^{4.0}$ cells was added to each well. The inoculated cells then were incubated at $37^{\circ} \mathrm{C}$ in an atmosphere with $5 \% \mathrm{CO}_{2}$ for 5 days, and the titers of PRV-specific NAbs were determined based on cytopathic effect (CPE), and the titers were expressed as the reciprocal of the highest dilution at which infection of the PK-15 cells was inhibited in $50 \%$ of the culture wells.

\section{qPCR}

The viral loads in the tissue samples of brain and lung from pigs were tested by $\mathrm{qPCR}$, using the primers specific for gB gene, gB- $f$ ( $5^{\prime}$-ACAAGTTCAAGGCCCACATCTAC-3'), gB-r (5'-GTCYGTGAAGCGGTTCGTGAT- $3^{\prime}$ ), and Probe-gB (FAMACGTCATCGTCACGACC-TARAM), on the CFX96 Touch Real-Time PCR Detection System (Bio-Rad). The copy number for each sample was expressed as $\log 10$ copies per gram of samples.

\section{Immunohistochemistry Assay}

Brain, cerebellum, tonsils, and lung samples were collected from the pigs from 3 groups for IHC assay. The samples were fixed with $10 \%$ formaldehyde, processed into paraffin blocks, and cut into sections. The sections were stained with hematoxylin and eosin. PRV antigen in the infected pigs' tissues was detected using an IHC with a PRV monoclonal antibody 3B5 (a gB-specific IgG antibody), as described previously $(28,29)$, and the HRP goat anti-mouse IgG (BTI, USA) served as the secondary antibody.

\section{Statistical Analysis}

Data were presented as mean $\pm \mathrm{SD}$. The survival rates were analyzed by the Kaplan-Meier test. The differences in plaque areas of viruses, body temperature, and antibody titers of piglets between groups were determined by using Student's $t$ test. Differences were considered statistically significant when $p<0.05$.

\section{RESULTS}

\section{Rescue of rHN1201 ${ }^{\mathrm{TK}-/ \mathrm{gE}-/ \mathrm{gl-} / 11 \mathrm{k}-/ 28 \mathrm{k}-}$ and Growth Properties}

The PCR product of SE(gI)/I-SceI/Amp/SE(28k) was applied to replace the fragment $\mathrm{SE}(\mathrm{gI}) / \mathrm{gI} / \mathrm{gE} / 11 \mathrm{k} / 28 \mathrm{k} / \mathrm{SE}(28 \mathrm{k})$ in pBAC-HN1201 ${ }^{\mathrm{TK}-}$ by homologous recombination in E.coli DY380 (Figure 1). The 5-gene deleted plasmid pBACHN1201 $1^{\text {TK- } / g E-/ g I-/ 11 k-/ 28 k-/ A m p ~}+$ was selected on an agar plate containing chloramphenicol and ampicillin, and further confirmed by sequencing. After digestion using ISceI, the linear plasmid was transformed into E. coli DY380 to remove the Amp gene, and then the plasmid pBACHN1201 $1^{\text {TK- } / g E-/ g I-/ 11 k-/ 28 k-~}$ was generated. The CPE could be observed at 72 hpi (Figure 2A). Plaques of rescued PRV were isolated and subjected to three rounds of purification. The virus was named $\mathrm{rHN} 1201^{\mathrm{TK}-/ \mathrm{gE}-/ \mathrm{gI}-/ 11 \mathrm{k}-/ 28 \mathrm{k}-}$, which lacked TK, gE, gI, $11 \mathrm{k}$, and part of the $28 \mathrm{k}$ genes compared with the parental virus HN1201.

As shown in Figure 2B, the growth features of rescued virus rHN1201 $1^{\mathrm{TK}-/ \mathrm{gE}-/ \mathrm{gI}-/ 11 \mathrm{k}-/ 28 \mathrm{k}-}$ were virtually identical to that of parental virus HN1201 in PK-15 cells. However, the plaque areas of the rescued virus were smaller than those formed by HN1201 in PK-15 cells (Figure 2C).

\section{Protection of Vaccinated Pigs After Challenge}

To determine the immunogenicity of rHN1201 $1^{\mathrm{TK}-/ \mathrm{gE}-/ \mathrm{gI}-/ 11 \mathrm{k}-/ 28 \mathrm{k}-}$, 15 piglets were selected for vaccination with $\mathrm{rHN} 1201^{\mathrm{TK}-/ \mathrm{gE}-/ \mathrm{gI}-/ 11 \mathrm{k}-/ 28 \mathrm{k}-}$ and BarthaK61, and subsequent challenge with the HN1201 strain at $21 \mathrm{dpv}$. The results showed that no clinical symptoms were observed in all pigs after vaccination. After challenge with HN1201 intranasally, all pigs in group 3 (unvaccinated) exhibited high fever $\left(40.5-41.7^{\circ} \mathrm{C}\right.$, Figure $\left.3 \mathrm{~A}\right)$, depression, anorexia, cough, and systematic neurological signs like convulsion and ataxia. All the unvaccinated pigs died at $6-7 \mathrm{dpc}$, and no pigs died after being vaccinated with $\mathrm{rHN} 1201^{\mathrm{TK}-/ \mathrm{gE}-/ \mathrm{gI}-/ 11 \mathrm{k}-/ 28 \mathrm{k}-}$ or Bartha-K61 (Figure 3B). As with the clinical signs of group 3 at 2-6 dpc, the pigs in group 2 (Bartha-K61) showed a transient period of high fever after challenge (three out of five pigs showed the temperature higher than $40.5^{\circ} \mathrm{C}$ for 4 days), and all pigs recovered from $7 \mathrm{dpi}$. In contrast, pigs in group 1 showed no clinical signs throughout the whole experiment. The result indicates that the vaccination with rHN1201 $1^{\mathrm{TK}-/ \mathrm{gE}-/ \mathrm{gI}-/ 11 \mathrm{k}-/ 28 \mathrm{k}-}$ could protect pigs against challenges with the new virulent PRV strain.

\section{Antibody Response After Vaccination and Challenge}

After vaccination, the levels of $\mathrm{gB}$ antibody increased in all the vaccinated groups. The results showed that the $\mathrm{gB}$ antibodies elicited by $\mathrm{rHN} 1201^{\mathrm{TK}-/ \mathrm{gE}-/ \mathrm{gI}-/ 11 \mathrm{k}-/ 28 \mathrm{k}-}$ in the serum samples were all positive at $10 \mathrm{dpv}$ and with the highest level at $21 \mathrm{dpv}$ before challenge ( $S / P$-value of 1.4$)$, which were earlier and higher than that of the Bartha-K61 group (not fully positive and $S / P$-value of 0.6 at $21 \mathrm{dpv}$ ) (Figure 4A), 


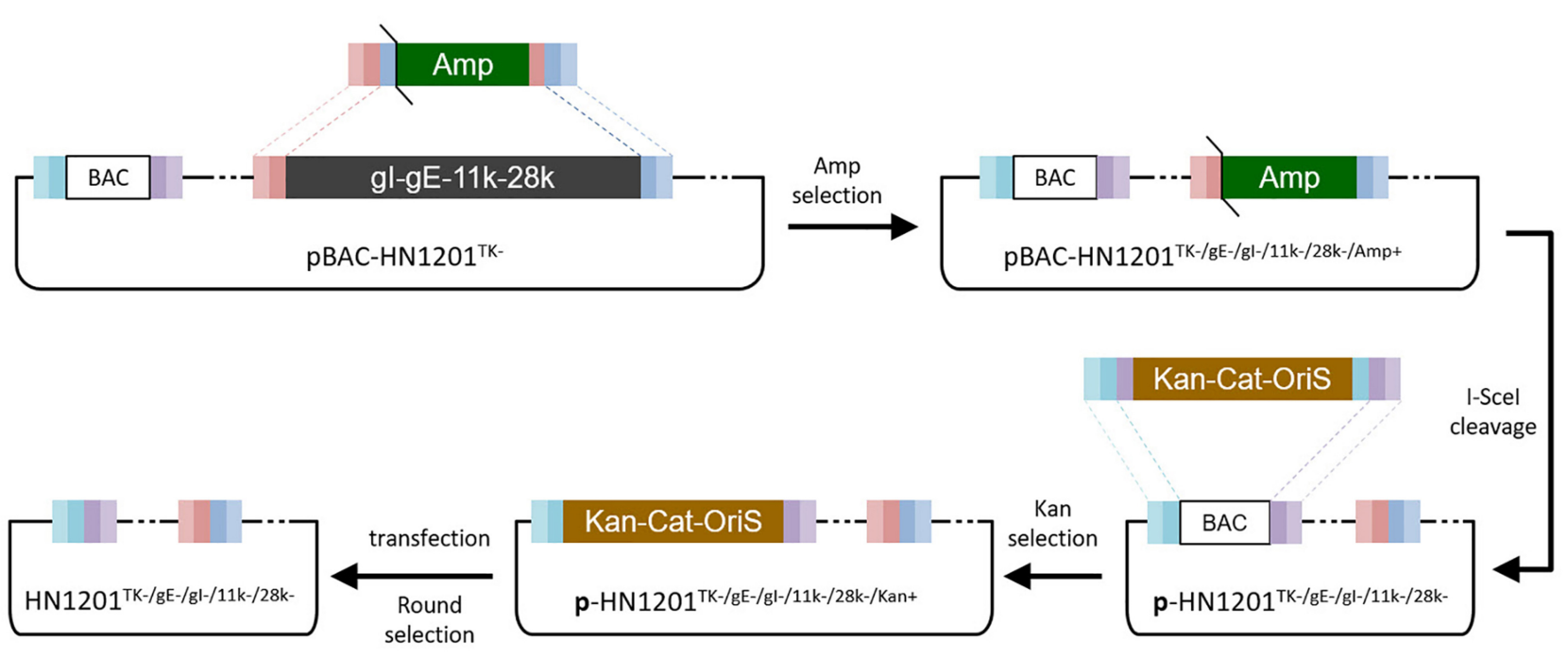

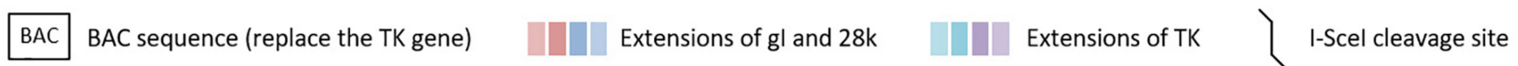

FIGURE 1 | Overview of strategies for the TK/gE/gl/11 k/28k deletion. Boxes of the same color represent identical sequences.

A

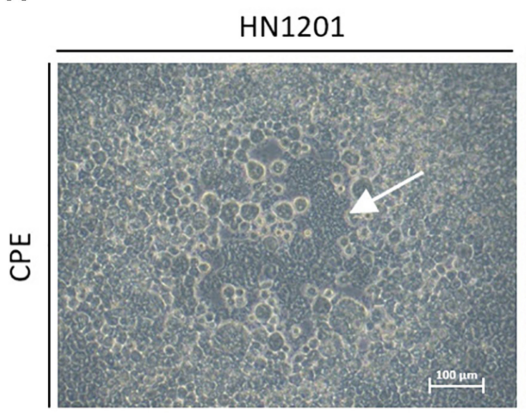

B

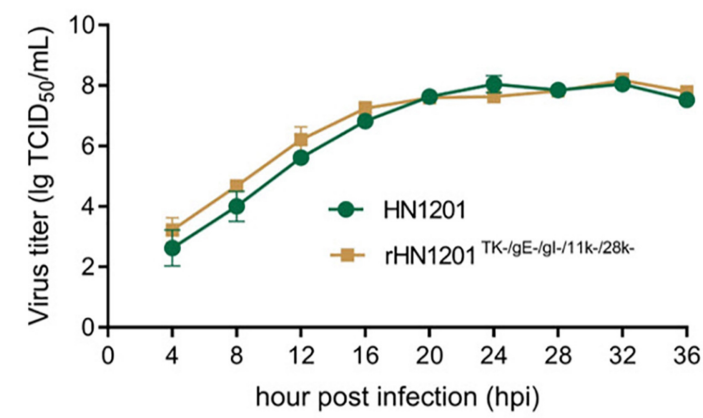

Uninfected cells

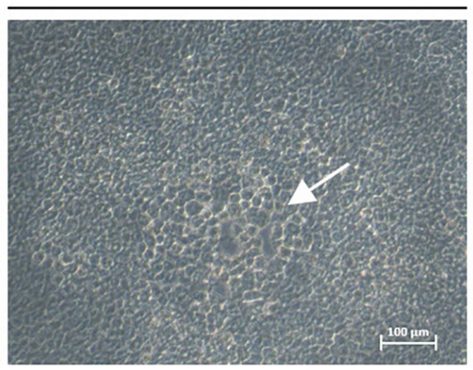

C

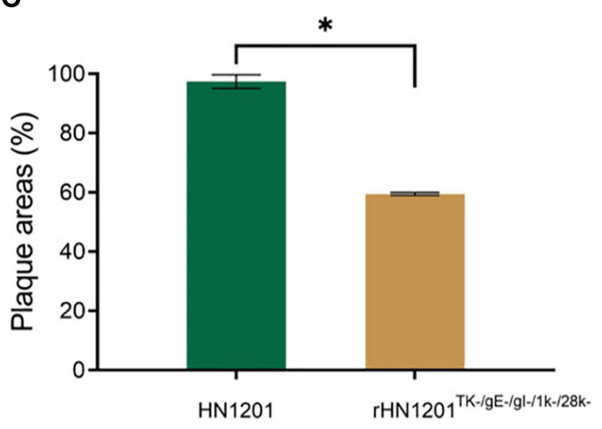

FIGURE 2 | Rescue and the characterization of recombinant PRV. (A) Cytopathic effect in Vero cells after transfection with recombinant PRV pBAC plasmids. The white arrow indicated the CPE. Bar $=100 \mu \mathrm{m}$. (B) Multiple growth curves of the chimeric viruses. The culture supernatants were collected at the indicated time points for the viral titer determination. (C) Plaque size of the recombinant viruses. The plaques were measured at $48 \mathrm{hpi}$. The plaque size induced by the parental virus was set at $100 \%$. Asterisk denotes a statistically significant difference $(p<0.05)$. 
A

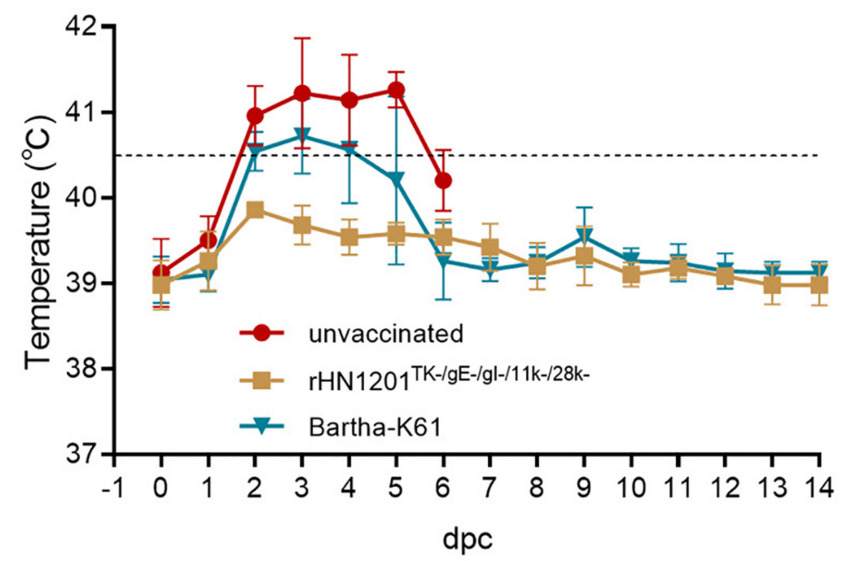

B

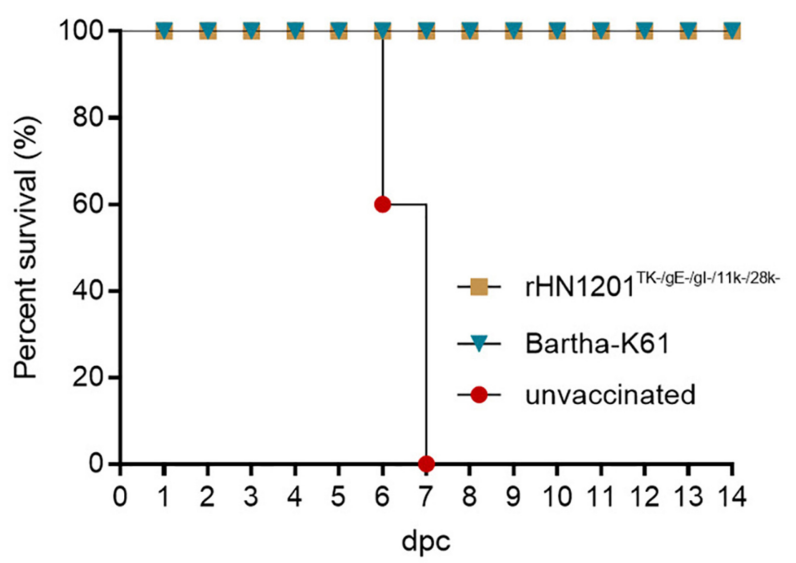

FIGURE 3 | Body temperature and survival rate of pigs after challenge. (A) Body temperature of pigs challenged with HN1201. (B) Survival rate of pigs challenged with HN1201. The survival rates were analyzed by the Kaplan Meier test.

indicating an enhanced protective effect of the recombinant PRV strain. The anti-PRV NAbs of pig serum elicited by rHN1201 $1^{\mathrm{TK}-/ \mathrm{gE}-/ \mathrm{gI}-/ 11 \mathrm{k}-/ 28 \mathrm{k}-}$ vaccination showed a high level against both the HN1201 and Bartha-K61 strains at 14 and $21 \mathrm{dpv}$, while anti-PRV NAbs of pig serum from the BarthaK61 vaccination group showed a significantly lower NA titer against HN1201 (Figure 4B), which indicated an insufficient effect of Bartha-K61 for protecting animals from infection of epidemic strains. Of note, no gB-specific antibodies and NAbs were detected in the unvaccinated group.

\section{Viral Load Assay After Challenge}

After the challenge, the viral loads of the tissue samples were detected in the DNA levels by qPCR. The results showed a significantly higher viral load in the lungs and nasal swab of the piglets in the $\mathrm{rHN} 1201^{\mathrm{TK}-/ \mathrm{gE}-/ \mathrm{gI}-/ 11 \mathrm{k}-/ 28 \mathrm{k}-}$ group than those in the Bartha-K61 group ( $p<0.05$ ) (Figure 4C), but not in the tissues of the brain and tonsil, which might be caused by the easier exposure of the respiratory tract to PRV.

\section{The Result of IHC Assay After Challenge}

In the IHC assay of tissue samples, as shown in Figure 5, the pigs in the unvaccinated group showed strong positive reaction in the tonsil, lung, brain, and trigeminal ganglion. While no positive reactions was detected in the tissues of unchallenged and vaccinated pigs recovered after the challenge, which indicated a sufficient protection effect of vaccination of $\mathrm{rHN} 1201^{\mathrm{TK}-/ \mathrm{gE}-/ \mathrm{gI}-/ 11 \mathrm{k}-/ 28 \mathrm{k}-}$.

\section{DISCUSSION}

The widely used PRV vaccines of classical strain, such as the strain Bartha-K61, were effective in PR control during the past several decades in China $(7,8)$. However, the re-emergent outbreaks of PR in the Bartha-K61 vaccinated pig farms since late 2011 indicated the insufficient protection of classical PRV vaccines (10-12, 16). In this study, a TK/gE/gI/11k/28k deleted PRV

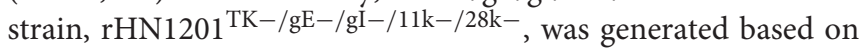
the RPV variant strain HN1201. The full protection in pigs immunized with $\mathrm{rHN} 1201^{\mathrm{TK}-/ \mathrm{gE}-/ \mathrm{gI}-/ 11 \mathrm{k}-/ 28 \mathrm{k}-}$ indicated that it is a safe and protective vaccine candidate to control the PR caused by new epidemic PRV variants.

The 3-kb deletion in the unique short (US) region of Bartha genome, partial loss of 28k, most of US7 (gI), and complete deletion of US8 (gE) and 11k (9) indicated an important role of these genes in the virulence determinant during infection. So, the genes of $\mathrm{gI}, \mathrm{gE}, 11 \mathrm{k}$, and $28 \mathrm{k}$ were selected for the construction of the 5-gene deleted PRV. The absence of the glycoprotein gE/gI complex in the Bartha genome partly explains the increased type I interferon response by plasmacytoid dendritic cells, and the potential of PRV Bartha vaccine strain to induce a strong type I interferon may contribute to the efficacy of the highly successful vaccine (9). In the future, the immunogenicity of the PRV 5gene deleted vaccine candidate will be evaluated at the level of cellular immunity.

As reported, PRV gE and gI are required for efficient cellto-cell spreading, gE/gI participates in the envelopment of nucleocapsids into cytoplasmic membrane vesicles (30), and delivery of virus particles to cell junctions would enhance virus spread (31). The viral protein of $11 \mathrm{k}$ interacts with a microtubule motor Kifla to mediate virus transport (32); this mechanism could be strengthened by other viral proteins such as $\mathrm{gE}$ and gI (33). The interaction among these viral proteins reveals the transmission mechanism of PRV and provides a perspective to understand PRV virulence.

In herpes simplex virus, gI and gE null mutants lead to the formation of small plaques (34), and in PRV, the deletion of $\mathrm{gI} / \mathrm{gE} / \mathrm{TK} / \mathrm{UL} 13$ also resulted in the formation of small plaques 

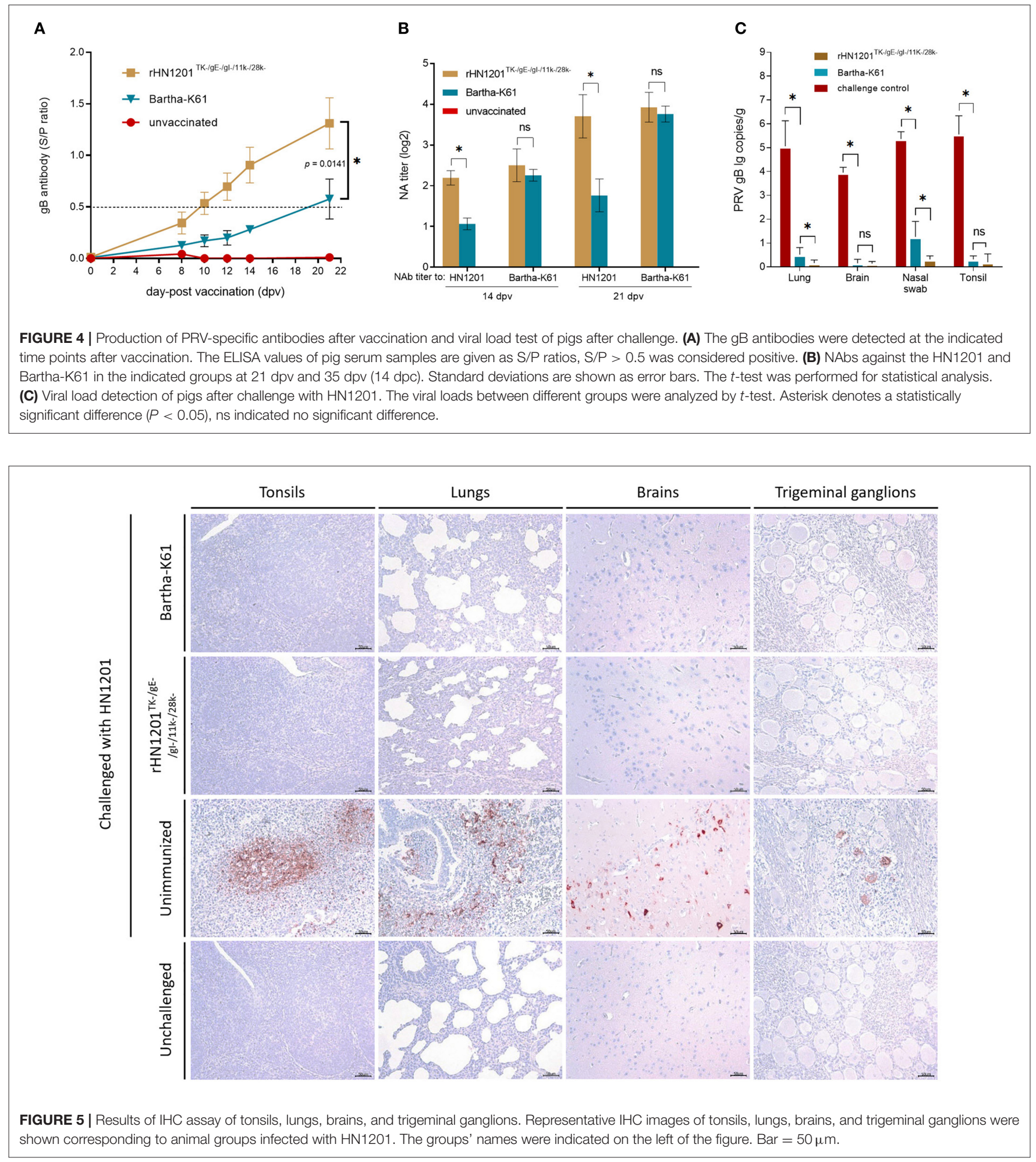

(35), which was consistent with the findings in our study. An attenuated PRV strain with the deletion of US8/11k/28k genes results in a higher titer and larger plaque size than that of WT treatment in Vero cells (36), while the larger size of the plaque formed by JS-2012 was considered induced by the cell adaption in Vero cells (120 passages).
The rapid improvement of biotechnology promoted the research of genetically modified PRV in recent years, such as the application of BAC system in gene deletion (16, 37-39), and the identification of foreign gene insertion sites in a PRV vector (40) and non-coding regions (UL11-10, UL35-36, UL4627, or US2-1). Notably, the method that allowed PRV genome 
manipulation by using the CRISPR/Cas9 system in PK15 cells was developed $(23,41)$ and showed a high positive rate without constructing homology arms, offering a simple and efficient method to manipulate the viral genome in the future, especially in the identification of potential new virulence genes for the highly safe vaccine development to control PR.

In summary, here, a recombinant PRV rHN1201 $1^{\mathrm{TK}-/ \mathrm{gE}-/ \mathrm{gI}-/ 11 \mathrm{k}-/ 28 \mathrm{k}-}$ was constructed by the BAC system, which elicited an earlier and higher level of gB antibody, and the NAbs elicited by $\mathrm{rHN} 1201^{\mathrm{TK}-/ \mathrm{gE}-/ \mathrm{gI}-/ 11 \mathrm{k}-/ 28 \mathrm{k}-}$ were effective against both PRV classical and variant strains. The rHN $1201^{\mathrm{TK}-/ \mathrm{gE}-/ \mathrm{gI}-/ 11 \mathrm{k}-/ 28 \mathrm{k}-}$ vaccination could provide effective protection against the challenge with the PRV variant. Therefore, it is a promising vaccine candidate for the prevention of the current epidemic of PR in China.

\section{DATA AVAILABILITY STATEMENT}

The original contributions presented in the study are included in the article/supplementary material, further inquiries can be directed to the corresponding authors.

\section{REFERENCES}

1. Pomeranz LE, Reynolds AE, Hengartner CJ. Molecular biology of pseudorabies virus: impact on neurovirology and veterinary medicine. Microbiol Mol Biol Rev. (2005) 69:462500. doi: 10.1128/MMBR.69.3.462-500.2005

2. Tan F, Li X, Tian K. Generating recombinant pseudorabies virus for use as a vaccine platform. Methods Mol Biol. (2017) 1581:79-96. doi: 10.1007/978-1-4939-6869-5_5

3. He W, Auclert LZ, Zhai X, Wong G, Zhang C, Zhu H, et al. Interspecies transmission, genetic diversity, and evolutionary dynamics of pseudorabies virus. J Infect Dis. (2019) 219:1705-15. doi: 10.1093/infdis/jiy731

4. Wang GS, Du Y, Wu JQ, Tian FL, Yu XJ, Wang JB. Vaccine resistant pseudorabies virus causes mink infection in China. BMC Vet Res. (2018) 14:20. doi: 10.1186/s12917-018-1334-2

5. Zhang L, Zhong C, Wang J, Lu Z, Liu L, Yang W, et al. Pathogenesis of natural and experimental Pseudorabies virus infections in dogs. Virol J. (2015) 12:44. doi: 10.1186/s12985-015-0274-8

6. Mock RE, Crandell RA, Mesfin GM. Induced latency in pseudorabies vaccinated pigs. Can J Comp Med. (1981) 45:56-9.

7. Luo Y, Li N, Cong X, Wang CH, Du M, Li L, et al. Pathogenicity and genomic characterization of a pseudorabies virus variant isolated from BarthaK61-vaccinated swine population in China. Vet Microbiol. (2014) 174:10715. doi: 10.1016/j.vetmic.2014.09.003

8. Mettenleiter TC. (1994). Pseudorabies (Aujeszky's disease) virus: state of the art. Acta Vet Hungar.42:153-177.

9. Lamote JAS, Kestens M, Van Waesberghe C, Delva J, De Pelsmaeker S, Devriendt $\mathrm{B}$, et al. The pseudorabies virus glycoprotein $\mathrm{gE} / \mathrm{gI}$ complex suppresses type i interferon production by plasmacytoid dendritic cells. $J$ Virol. (2017) 91:16. doi: 10.1128/JVI.02276-16

10. Fan J, Zeng X, Zhang G, Wu Q, Niu J, Sun B, et al. Molecular characterization and phylogenetic analysis of pseudorabies virus variants isolated from Guangdong province of southern China during 2013-2014. J Vet Sci. (2016) 17:369-75. doi: 10.4142/jvs.2016.17. 3.369

11. Hu RM, Zhou Q, Song WB, Sun EC, Zhang MM, He QG, et al. Novel pseudorabies virus variant with defects in TK, $\mathrm{gE}$ and gI protects growing pigs against lethal challenge. Vaccine. (2015) 33:5733-40. doi: 10.1016/j.vaccine.2015. 09.066

(2015)

\section{ETHICS STATEMENT}

The animal study was reviewed and approved by Animal Care and Ethics Committee of National Research Center for Veterinary Medicine.

\section{AUTHOR CONTRIBUTIONS}

FT, BH, and KT conceived and designed the research. SY, XB, YZ, LG, TW, and YW conducted the experiments. FT, YZ, and $\mathrm{BH}$ analyzed the data. SY, FT, BH, and $\mathrm{KT}$ conceived the study, carried out additional analyses, and finalized the manuscript. All authors contributed to the article and approved the submitted version.

\section{FUNDING}

This study was supported by the project of $R \& D$ and industrialization of genetically engineered vaccines for swine pseudorabies, swine ring, and Mycoplasma hyopneumoniae (201200211200).

12. Yu X, Zhou Z, Hu D, Zhang Q, Han T, Li X, et al. Pathogenic pseudorabies virus, China 2012. Emerg Infect Dis. (2014) 20:102-4. doi: 10.3201/eid2001.130531

13. Gu Z, Hou C, Sun H, Yang W, Dong J, Bai J, et al. Emergence of highly virulent pseudorabies virus in southern China. Can J Vet Res. (2015) 79:221-8.

14. An TQ, Peng JM, Tian ZJ, Zhao HY, Li N, Liu YM, et al. Pseudorabies virus variant in Bartha-K61-vaccinated pigs, China, 2012. Emerg Infect Dis. (2013) 19:1749-55. doi: 10.3201/eid1911.130177

15. Wu R, Bai C, Sun J, Chang S, Zhang X. Emergence of virulent pseudorabies virus infection in northern China. J Vet Sci. (2013) 14:3635. doi: 10.4142 /jvs.2013.14.3.363

16. Gu Z, Dong J, Wang J, Hou C, Sun H, Yang W, et al. A novel inactivated $\mathrm{gE} / \mathrm{gI}$ deleted pseudorabies virus (PRV) vaccine completely protects pigs from an emerged variant PRV challenge. Virus Res. (2015) 195:57-63. doi: 10.1016/j.virusres.2014.09.003

17. Bergmann T, Moore C, Sidney J, Miller D, Tallmadge R, Harman RM, et al. The common equine class I molecule Eqca- $1^{*} 00101$ (ELA-A3.1) is characterized by narrow peptide binding and $\mathrm{T}$ cell epitope repertoires. Immunogenetics. (2015) 67:675-89. doi: 10.1007/s00251-015-0872-z

18. Cottingham MG, Gilbert SC. Rapid generation of markerless recombinant MVA vaccines by en passant recombineering of a selfexcising bacterial artificial chromosome. J Virol Methods. (2010) 168:233-6. doi: 10.1016/j.jviromet.2010.04.012

19. Tischer BK, Kaufer BB, Sommer M, Wussow F, Arvin AM, Osterrieder N A self-excisable infectious bacterial artificial chromosome clone of varicellazoster virus allows analysis of the essential tegument protein encoded by ORF9. J Virol. (2007) 81:13200-8. doi: 10.1128/JVI.01148-07

20. Yang CH, Liang CT, Jiang ST, Chen KH, Yang CC, Cheng ML, et al. A novel murine model expressing a chimeric mSCARB2/hSCARB2 receptor is highly susceptible to oral infection with clinical isolates of enterovirus 71. J Virol. (2019) 93:e00183-19. doi: 10.1128/JVI.00183-19

21. Tischer BK, Kaufer BB. Viral bacterial artificial chromosomes: generation, mutagenesis, and removal of mini-F sequences. J Biomed Biotechnol. (2012) 2012:472537. doi: 10.1155/2012/472537

22. Wang J, Cui X, Wang X, Wang W, Gao S, Liu X, et al. Efficacy of the Bartha$\mathrm{K} 61$ vaccine and a $\mathrm{gE}(-) / \mathrm{gI}(-) / \mathrm{TK}(-)$ prototype vaccine against variant porcine pseudorabies virus (vPRV) in piglets with sublethal challenge of vPRV. Res Vet Sci. (2020) 128:16-23. doi: 10.1016/j.rvsc.2019.10.005

23. Zhao $\mathrm{Y}$, Wang LQ, Zheng $\mathrm{HH}$, Yang YR, Liu F, Zheng LL, et al. Construction and immunogenicity of a gE/gI/TK-deleted PRV 
based on porcine pseudorabies virus variant. Mol Cell Probes. (2020) 53:101605. doi: 10.1016/j.mcp.2020.101605

24. Brideau AD, Card JP, Enquist LW. Role of pseudorabies virus Us9, a type II membrane protein, in infection of tissue culture cells and the rat nervous system. J Virol. (2000) 74:834-45. doi: 10.1128/JVI.74.2.834-845.2000

25. Kratchmarov R, Taylor MP, Enquist LW. Role of Us9 phosphorylation in axonal sorting and anterograde transport of pseudorabies virus. PLoS ONE. (2013) 8:e58776. doi: 10.1371/journal.pone.0058776

26. Lomniczi B, Watanabe S, Ben-Porat T, Kaplan AS. Genetic basis of the neurovirulence of pseudorabies virus. J Virol. (1984) 52:198-205. doi: 10.1128/jvi.52.1.198-205.1984

27. Lyu C, Wang S, Sun M, Tang Y, Peng J, Tian Z, et al. Deletion of pseudorabies virus US2 gene enhances viral titers in a porcine cerebral cortex primary culture system. Virus Genes. (2018) 54:40613. doi: 10.1007/s11262-018-1552-5

28. Yang QY, Sun Z, Tan FF, Guo LH, Wang YZ, Wang J, et al. Pathogenicity of a currently circulating Chinese variant pseudorabies virus in pigs. World J Virol. (2016) 5:23-30. doi: 10.5501/wjv.v5.i1.23

29. Zhang C, Guo L, Jia X, Wang T, Wang J, Sun Z, et al. Construction of a triple gene-deleted Chinese Pseudorabies virus variant and its efficacy study as a vaccine candidate on suckling piglets. Vaccine. (2015) 33:24327. doi: 10.1016/j.vaccine.2015.03.094

30. Brack AR, Klupp BG, Granzow H, Tirabassi R, Enquist LW, Mettenleiter TC. Role of the cytoplasmic tail of pseudorabies virus glycoprotein $\mathrm{E}$ in virion formation. J Virol. (2000) 74:4004-16. doi: 10.1128/JVI.74.9.4004-401 6.2000

31. Johnson DC, Webb M, Wisner TW, Brunetti C. Herpes simplex virus gE/gI sorts nascent virions to epithelial cell junctions, promoting virus spread. $J$ Virol. (2001) 75:821-33. doi: 10.1128/JVI.75.2.821-833.2001

32. Kramer T, Greco TM, Taylor MP, Ambrosini AE, Cristea IM, Enquist LW. Kinesin-3 mediates axonal sorting and directional transport of alphaherpesvirus particles in neurons. Cell Host Microbe. (2012) 12:80614. doi: 10.1016/j.chom.2012.10.013

33. Kratchmarov R, Kramer T, Greco TM, Taylor MP, Ch'ng TH, Cristea IM, et al. Glycoproteins gE and gI are required for efficient KIF1A-dependent anterograde axonal transport of alphaherpesvirus particles in neurons. J Virol. (2013) 87:9431-40. doi: 10.1128/JVI.01317-13

34. Farnsworth A, Johnson DC. Herpes simplex virus gE/gI must accumulate in the trans-Golgi network at early times and then redistribute to cell junctions to promote cell-cell spread. I Virol. (2006) 80:316779. doi: 10.1128/JVI.80.7.3167-3179.2006

35. Lv L, Liu X, Jiang C, Wang X, Cao M, Bai J, et al. Pathogenicity and immunogenicity of a gI/gE/TK/UL13-gene-deleted variant pseudorabies virus strain in swine. Vet Microbiol. (2021) 258:109104. doi: 10.1016/j.vetmic.2021.109104

36. Liang C, Tong W, Zheng H, Liu F, Wu J, Li G, et al. A hightemperature passaging attenuated Pseudorabies vaccine protects piglets completely against emerging PRV variant. Res Vet Sci. (2017) 112:10915. doi: 10.1016/j.rvsc.2017.02.008

37. Hubner A, Keil GM, Kabuuka T, Mettenleiter TC, Fuchs W. Efficient transgene insertion in a pseudorabies virus vector by CRISPR/Cas9 and marker rescue-enforced recombination. J Virol Methods. (2018) 262:3847. doi: 10.1016/j.jviromet.2018.09.009

38. Wang T, Tong W, Ye C, Yu Z, Chen J, Gao F, et al. Construction of an infectious bacterial artificial chromosome clone of a pseudorabies virus variant: reconstituted virus exhibited wild-type properties in vitro and in vivo. J Virol Methods. (2018) 259:106-15. doi: 10.1016/j.jviromet.2018.06.004

39. Zhang C, Liu Y, Chen S, Qiao Y, Guo M, Zheng Y, et al. A gD\&gC-substituted pseudorabies virus vaccine strain provides complete clinical protection and is helpful to prevent virus shedding against challenge by a Chinese pseudorabies variant. BMC Vet Res. (2019) 15:2. doi: 10.1186/s12917-018-1766-8

40. Zhang C, Guo S, Guo R, Chen S, Zheng Y, Xu M, et al. Identification of four insertion sites for foreign genes in a pseudorabies virus vector. BMC Vet Res. (2021) 17:190. doi: 10.1186/s12917-021-02887-w

41. Xu A, Qin C, Lang Y, Wang M, Lin M, Li C, et al. A simple and rapid approach to manipulate pseudorabies virus genome by CRISPR/Cas9 system. Biotechnol Lett. (2015) 37:1265-72. doi: 10.1007/s10529-015-1796-2

Conflict of Interest: The authors declare that the research was conducted in the absence of any commercial or financial relationships that could be construed as a potential conflict of interest.

Publisher's Note: All claims expressed in this article are solely those of the authors and do not necessarily represent those of their affiliated organizations, or those of the publisher, the editors and the reviewers. Any product that may be evaluated in this article, or claim that may be made by its manufacturer, is not guaranteed or endorsed by the publisher.

Copyright (C) 2022 Yan, Huang, Bai, Zhou, Guo, Wang, Shan, Wang, Tan and Tian. This is an open-access article distributed under the terms of the Creative Commons Attribution License (CC BY). The use, distribution or reproduction in other forums is permitted, provided the original author(s) and the copyright owner(s) are credited and that the original publication in this journal is cited, in accordance with accepted academic practice. No use, distribution or reproduction is permitted which does not comply with these terms. 